\title{
Pre-diagnostic management of patients suspicious of deep vein thrombosis
}

\author{
Frans Santosa ${ }^{1}$, Andreas Raming ${ }^{2}$, Christian Moerchel ${ }^{3}$, Knut Kröger ${ }^{1,3}$ \\ 1. Department of Vascular Medicine, HELIOS Klinikum Krefeld, Germany. 2. General Practitioner Practice, Osnabrück, \\ Germany. 3. Thrombose-Initiative e.V., Mainz, Germany.
}

Correspondence: Knut Kröger. Address: Klinik für Gefäßmedizin, Helios Klinikum Krefeld, Lutherplatz 40, 47805 Krefeld, Germany. E-mail: knut.kroeger@helios-kliniken.de

Received: November 25, 2013

DOI : $10.5430 /$ jha.v3n5p34
Accepted: March 22, 2014

URL: http://dx.doi.org/10.5430/jha.v3n5p34

Online Published: April 11, 2014

Abstract

Background: We analysed the feasibility of the 9th ACCP-guidelines recommendation of starting therapeutic anticoagulation in patients with a high suspicion of deep vein thrombosis (DVT) and tried to answer the question as to whether it generates a relevant over- or under-use of anti-coagulants in the period prior to the definitive diagnosis.

Patients and methods: From March to May 2013 we included 98 consecutive out-patients (mean age $63 \pm 17$ years, 39 males) suspected of DVT, classifying them according to the 9th ACCP-guidelines recommendations into two groups with high and low clinical suspicion. Those with a high suspicion (Wells Score $\geq 2$ and elevated DDimer concentration) initially received Rivaroxaban $15 \mathrm{mg}$ orally.

Results: Out of the 80 patients with a high clinical suspicion, $15(19 \%)$ received therapeutic anti-coagulation without any medical necessity because DVT was finally excluded. Out of the 10 patients with a low clinical suspicion, $2(20 \%)$ with a finally proven DVT might have benefited from initial therapeutic anti-coagulation. Females were at a slightly higher risk of receiving therapeutic anti-coagulation unnecessarily. Out of the 45 females with a high clinical suspicion, who received therapeutic anti-coagulation, DVT was excluded in $9(20 \%)$. In males it was $6(17 \%)$ out of 35 patients. The costs for those 80 patients accepting initial anti-coagulation by taking Rivaroxaban $15 \mathrm{mg}$ were $€ 312$. By using Certoparin 8000 I.E. the cost would have been $€ 792$, which is $150 \%$ higher compared to Rivaroxaban within in the same period.

Conclusion: Defining patients to have a high suspicion for DVT by Wells score and DDimer is associated with an over-use of therapeutic anticoagulation in almost every fifth patients.

\section{Key words}

Deep vein thrombosis, Wells score, Rivaroxaban, Low molecular weight heparin

\section{Introduction}

Diagnostic and treatment of deep vein thrombosis (DVT) is a rather standardised process which has been described in different guidelines in the recent years. The pre-diagnostic handling of people suspicious for DVT has not been specifically addressed in these guidelines. This changed with the publication of the current 9 th ACCP guidelines ${ }^{[1]}$. The 8th ACCP guidelines generally recommended "If the clinical suspicion is high, or if there is a delay before diagnostic testing can be performed, treatment should be started before such testing" ${ }^{2]}$. In the 2012 version of the guidelines the 
authors say that "The decision regarding treatment while awaiting test results requires balancing minimizing thrombotic complications in patients with DVT and avoiding bleeding in those without DVT". First, the higher the clinical suspicion for DVT the shorter the acceptable interval without treatment until results of diagnostic testing become available. Second, the higher the risk of bleeding the longer the acceptable interval without treatment until results are available. This recommendation is attributed as Grade $2 \mathrm{c}$ level and no randomised controlled trial has been addressing this question till now.

Thus, we analysed the feasibility of this recommendation and tried to answer the question as to whether it generates an over- or under-use of anti-coagulants in the period prior to the definitive proof or exclusion of a DVT.

\section{Patient and methods}

From March 2013 to May 2013 we included 98 consecutive out-patients suspected of deep vein thrombosis at a general practitioner (GP) practice in Osnabrück, Germany.

Patients suspected to have DVT were classified according to the recommendations of the 12th ACCP guidelines into two groups:

Patients with a high clinical suspicion of acute DVT: A high clinical suspicion was defined as a Wells score of 2 or more points ${ }^{[3]}$ and an increased DDimer (DD) concentration. These patients were treated once the DVT was suspected by the GP, independent of the time to a compression ultrasound (CUS) as the final diagnostic test.

Patients with a low clinical suspicion of acute DVT: A low clinical suspicion was defined as a Wells score of less than 2 points but an increased DD concentration. These patients were treated only if the diagnostic test could not be managed within 24 hours.

In case of a negative DD DVT was excluded. We did not define a group with an intermediate clinical suspicion. They could have been defined by clinical investigation using the Wells score. According to the levels of DD, all patients could be classified as those with either high or low suspicion.

In contrast to the 9th ACCP recommendations, anti-coagulation was performed by oral application of Rivaroxaban $15 \mathrm{mg}$ once and not by s.c. application of a low molecular heparin (LMWH). DD concentration was determined using the Alere Triage ${ }^{\circledR}$ DD Panel (Alere GmbH, Cologne, Germany). This is a rapid, quantitative immunoassay giving final results after 15 minutes. DD concentrations of $400 \mathrm{ng} / \mathrm{ml}$ or below are considered to be within the normal range.

Patients suspected to have DVT were sent to the nearest hospital for a CUS (Siemens Acuson X300 PE, Germany). According to the hospital's decision, some patients with proven DVT were treated as in-patients, whilst others were treated as out-patients. All patients finally came back to the GP on the same day or within the next few days. If they had not been back within one week, the hospital doctor was contacted. Thus, we were able to document the time to CUS and the result as either excluded or proven DVT.

\section{Results}

Ninety eight consecutive patients were enrolled (mean age was $63 \pm 17$ years, 39 were males).

According to the Wells Score only 10 (seven females, three males) had a score of less than 2, defined as a low suspicion (see Table). Out of these 10 patients, nine (90\%) had an increased DD concentration, but in only two (20\%) of them DVT was finally proven. One patient received Rivaroxaban $15 \mathrm{mg}$ because the time to a compression ultrasound was going to be more than $24 \mathrm{~h}$. 
Table. List of the results for the pre-test probability according to the Wells score. Given are the numbers of patients, the different scores, the number and rates of those with elevated DD (pos DD) and of those with proven DVT.

\begin{tabular}{|c|c|c|c|c|c|c|c|c|c|}
\hline \multirow{3}{*}{$\begin{array}{l}\begin{array}{l}\text { Age, } \\
\text { years }\end{array} \\
\text { Score }\end{array}$} & \multicolumn{3}{|c|}{ all $(n=98)$} & \multicolumn{3}{|c|}{ females $(n=59)$} & \multicolumn{3}{|c|}{ males $(n=39)$} \\
\hline & \multicolumn{3}{|c|}{$63 \pm 17$} & \multicolumn{3}{|c|}{$59 \pm 19$} & \multicolumn{3}{|c|}{$70 \pm 12$} \\
\hline & $\mathrm{n}$ & $\begin{array}{l}\text { pos DD } \\
81(83 \%)\end{array}$ & $\begin{array}{l}\text { DVT proven } \\
67(68 \%)\end{array}$ & $\mathrm{n}$ & $\begin{array}{l}\text { pos DD } \\
47(79 \%)\end{array}$ & $\begin{array}{l}\text { DVT proven } \\
37(63 \%)\end{array}$ & $\mathrm{n}$ & $\begin{array}{l}\text { pos DD } \\
35(90 \%)\end{array}$ & $\begin{array}{l}\text { DVT proven } \\
29(74 \%)\end{array}$ \\
\hline 1 & 10 & $9(90 \%)$ & $2(20 \%)$ & 7 & $6(86 \%)$ & $1(14 \%)$ & 3 & $3(100 \%)$ & $1(33 \%)$ \\
\hline 2 & 23 & $17(74 \%)$ & $10(44 \%)$ & 18 & $12(66 \%)$ & $6(33 \%)$ & 5 & $5(100 \%)$ & $4(80 \%)$ \\
\hline 3 & 25 & $17(68 \%)$ & $19(76 \%)$ & 13 & $8(62 \%)$ & $10(77 \%)$ & 12 & $9(75 \%)$ & $9(75 \%)$ \\
\hline 4 & 25 & $25(100 \%)$ & $22(88 \%)$ & 15 & $15(100 \%)$ & $15(100 \%)$ & 10 & $10(100 \%)$ & $7(70 \%)$ \\
\hline 5 & 10 & $8(80 \%)$ & $9(80 \%)$ & 5 & $4(80 \%)$ & $5(100 \%)$ & 5 & $4(80 \%)$ & $4(80 \%)$ \\
\hline 6 & 5 & $5(100 \%)$ & $5(100 \%)$ & 1 & $1(100 \%)$ & $1(100 \%)$ & 4 & $4(100 \%)$ & $4(100 \%)$ \\
\hline$\geq 2$ & 88 & $72(82 \%)$ & $65(74 \%)$ & 52 & $40(77 \%)$ & $37(71 \%)$ & 36 & $32(89 \%)$ & $28(78 \%)$ \\
\hline
\end{tabular}

Out of the 88 patients with a Wells Score of 2 and more, only 72 (81\%) (52 females, 36 males) had increased DD concentrations and in 65 (74\%) DVT was finally proven. All of them should have received Rivaroxaban $15 \mathrm{mg}$, but eight (seven females, one male) refused taking the drug without proven diagnosis.

Thus, out of those 80 with a high clinical suspicion, who took Rivaroxaban $15 \mathrm{mg}, 65(81 \%)$ had a proven DVT and in 15 $(19 \%)$ a DVT was excluded. Thus, finally, $15(19 \%)$ patients received therapeutic anti-coagulation without any medical need. Out of those with a low clinical suspicion, $2(20 \%)$ of the patients with proven DVT might have had a benefit from an initial therapeutic anti-coagulation. One of these two patients had received anti-coagulation by chance because the time to a definitive diagnosis by compression ultrasound was going to be more than 24 hours.

Females were at higher risk to receive therapeutic anti-coagulation unnecessarily. Of the 45 females with a high clinical suspicion, who took Rivaroxaban $15 \mathrm{mg}$, nine (20\%) received therapeutic anti-coagulation, although DVT was finally excluded. In males it were $6(17 \%)$ out of 35 patients. In those with a low clinical suspicion one female and one male with finally proven DVT should have had initial therapeutic anti-coagulation.

Clinically manifest bleedings within 24 hours of the initial pre-diagnostic application of Rivaroxaban were not documented.

\section{Costs}

Estimates for the costs of one therapeutic dose of anticoagulation in Germany were made. In Germany the current costs for one dose of Rivaroxaban $15 \mathrm{mg}$ are $€ 3.90$ and for one dose of the LMWH Certoparin 8000 I.E. $€ 9.90$. The costs for those 80 patients that accepted initial anti-coagulation by taking Rivaroxaban $15 \mathrm{mg}$ were $€ 312$. If using Certoparin 8000 I.E., the costs would have been $€ 792$, which is $150 \%$ higher.

\section{Discussion}

This is the first study analysing the feasibility of the recommendation of the 9th ACCP guideline of initiating therapeutic anti-coagulation in patients with a high suspicion for DVT, as no trial has been addressing this question to date ${ }^{[2]}$. The definition of high suspicion depends on the regional setting and the results might be different in other settings. Pre-diagnostic therapeutic anticoagulation with Rivaroxaban $15 \mathrm{mg}$ in patients suspected of DVT seems to be safe. The acceptance by patients is rather high and, compared to LMWH, it is much cheaper in Germany.

A number of studies have analysed different algorithm to diagnose DVT. The standard diagnostic algorithm for patients with clinically suspected DVT starts with the Wells rule to determine pre-test probability followed by a quantitative DD 
test in case of an unlikely clinical probability. In patients with a "DVT unlikely" score (0-1 point) and a DD level $<0.5$ $\mu \mathrm{g} / \mathrm{ml}$ DVT can be safely ruled out ${ }^{[4-6]}$. Using the Wells score and DD to define patients with a high clinical suspicion of acute DVT, there was one fifth (19\%) of these patients receiving one therapeutic dose of Rivaroxaban, although they finally did not have DVT. On the other hand, one fifth (only two patients in our setting) should have received anticoagulation because they did have DVT, despite a low suspicion. Thus, there is an acceptable over- and under-use of therapeutic anti-coagulation, respectively.

DD is a degradation product of a cross-linked fibrin blood clot that is typically elevated in patients with acute VTE, but also by a variety of non-thrombotic disorders, including recent major surgery, haemorrhage, trauma, pregnancy or cancer. The diagnostic value of DD in the exclusion of proximal DVT is well established, but it is less well known in the exclusion of distal (infrapopliteal) DVT. All assays showed high sensitivity for proximal DVT (range 97\%-100\%), but poor sensitivity for distal DVT (range 78\%-93\%). However, a negative DD test result combined with a low pretest probability (PTP) exhibited a negative predictive value of $100 \%$ for all DVTs, including proximal, tibial/fibular and muscle DVTs $^{[7,8]}$. Thus, the diagnostic sensitivity of DD played an important role in our analysis.

The percentage of patients with a high probability Wells clinical pre-test score is higher in men than in women $(67.0 \% \mathrm{vs}$. $57.0 \%, p<.001)$. Although the score equally discriminates risk groups for DVT in both sexes, women were more frequently referred for a diagnostic work-up for DVT than men, but the prevalence of DVT was higher in men and their thrombotic events were more severe ${ }^{[9]}$. This fact might explain the higher number of females receiving therapeutic anti-coagulation, despite exclusion of DVT in our population. The difference could have even been higher, but more females refused taking Rivaroxaban compared to males.

Data regarding the clinical necessity for treatment whilst awaiting test results in patients suspected to have DVT are missing. A German registry involving 4,976 patients with clinically suspected DVT of the leg in 2005 showed that about $60 \%$ of these patients were referred to specialists by their family physicians on the day of initial presentation, $18 \%$ on the next day, $8 \%$ on the second or third day and about $15 \%$ on the fourth day or even later ${ }^{[10]}$. Patients with confirmed DVT were treated about twice as often with anti-thrombotics prior to diagnosis than those without DVT (25\% vs. $12 \%)^{[11]}$. Thus, in this 8-year-old registry there was a much greater delay than in our population. Considering the recent ACCP recommendation, around one third of the patients should have had anti-coagulation prior to diagnosis just because of the time delay. Generally, there was a low use of initial anti-coagulation prior to diagnosis. Thus, the awareness of the possible positive effects of therapeutic anti-coagulation to prevent thrombus apposition was low. It might have increased in recent years, but we do not have specific data.

The awareness for pre-treatment seems to be higher in recent studies performed for the new oral anti-coagulants. In the EINSTEIN-DVT study around $70 \%$ of the included patients with proven DVT received pre-treatment with LMWH, heparin or fondaparinux prior to randomisation ${ }^{[12]}$. Unfortunately, we do not know the rate of the $70 \%$ who were treated before the diagnosis was made. Symptomatic recurrent VTE was documented in $1.9 \%$ and $2.0 \%$ of those without and in $2.1 \%$ and $3.4 \%$ of those with pre-treatment of those who were randomised to Rivaroxaban and Enoxaprin/ vitamin-K-antagonists (VKA), respectively. Thus, there is a small difference in the VKA group only.

Data from the RIETE registry were published analysing the role of sub-optimal doses of LWMH in acute venous thromboembolism retrospectively ${ }^{[4]}$. 1,547 patients received sub-optimal LMWH (mean $=122 \mathrm{UI} \mathrm{kg}^{-1}$ day $^{-1}$ ) and 8,977 patients received full-dose LMWH (mean $=191 \mathrm{UI} \mathrm{kg}^{-1}$ day $^{-1}$ ). The sub-optimal group included significantly more patients with recent major bleeding, weight more than $100 \mathrm{~kg}$, raised creatinine or DVT. No significant differences in mortality rate (7.7\% vs. $7.8 \%)$, VTE recurrence $(2.7 \%$ vs. $2.3 \%)$, or fatal haemorrhage $(0.6 \%$ vs. $0.6 \%)$ occurred between the sub-optimal and the standard group. Together, the two recent studies do not suggest that the effect of prevention of thrombus apposition by initial therapeutic anti-coagulation is really high. 
Despite this lack of data, the need for immediate anti-coagulation seems to be more important today than the need to make the diagnosis as soon as possible. Wells at al. wrote in a recent review ${ }^{[14]}$ : "Patients in whom there is a moderate or high clinical suspicion of venous thromboembolism (VTE) may receive an injection of LMWH in doses designed to treat acute VTE. Diagnostic imaging can then be arranged on an elective basis the following day. Because LMWH is a safe and effective therapy for patients with proven VTE, it also provides adequate protection for patients with suspected VTE". We think that applying a therapeutic anticoagulation to a patient that finally does not have an indication requires a very safe drug. Any bleeding complications are not acceptable and in the event of a dispute, difficult to justify.

\section{Conclusion}

Defining patients to have a high suspicion for DVT by Wells score and DD is associated with an over-use of therapeutic anticoagulation in almost every fifth patients. According to the guidelines, this overuse should be accepted because of the presumed advantages of this strategy in this group of patients. Using Rivaroxaban it can be performed safely and easily with a high acceptance and lower cost than using LMWH, at least in Germany. The specific cost/benefit ratio of initial therapeutic anti-coagulation has to be investigated in randomised controlled studies.

\section{Reference}

[1] Kearon C, Kahn SR, Agnelli C, Goldhaber S, Raskob GE, Comerota AJ. Practice Guidelines Therapy for Venous Thromboembolic Disease. Chest. 2008; 133: 454-545. PMid: 18574272. http://dx.doi.org/10.1378/chest.08-0658

[2] Kearon C, Akl EA, Comerota AJ, Prandoni P, Bounameaux H, Goldhaber SZ, et al. Antithrombotic Therapy for VTE Disease. Chest. 2012; 141(2) (Suppl): e419S-e494S.

[3] Wells PS, Anderson DR, Rodger M, Forgie M, Kearon C, Dreyer J, et al. Evaluation of D-dimer in the diagnosis of suspected deep-vein thrombosis. N Engl J Med. 2003; 349: 1227-35. PMid: 14507948. http://dx.doi.org/10.1056/NEJMoa023153

[4] Anderson DR, Kovacs MJ, Kovacs G, Stiell I, Mitchell M, Khoury V, et al. Combined use of clinical assessment and d-dimer to improve the management of patients presenting to the emergency department with suspected deep vein thrombosis (the EDITED Study). J Thromb Haemost. 2003; 1: 645-51. PMid: 12871396. http://dx.doi.org/10.1046/j.1538-7836.2003.00131.x

[5] Goodacre S, Sampson F, Stevenson M, Wailoo A, Sutton A, Thomas S, et al. Measurement of the clinical and cost-effectiveness of non-invasive diagnostic testing strategies for deep vein thrombosis. Health Technol Assess. 2006; 10: 1-168, iii-iv. PMid: 16707072.

[6] Michiels JJ, Gadisseur A, Van Der Planken M, Schroyens W, De Maeseneer M, Hermsen JT, et al. A critical appraisal of non-invasive diagnosis and exclusion of deep vein thrombosis and pulmonary embolism in outpatients with suspected deep vein thrombosis or pulmonary embolism: how many tests do we need? Int Angiol. 2005; 24: 27-39. PMid: 15876996.

[7] Di Nisio M, Squizzato A, Rutjes AW, et al. Diagnostic accuracy of D-dimer test for exclusion of venous thromboembolism: a systematic review. J Thromb Haemost. 2007; 5: 296-304. PMid: 17155963. http://dx.doi.org/10.1111/j.1538-7836.2007.02328.x

[8] Luxembourg B, Schwonberg J, Hecking C, Schindewolf M, Zgouras D, Lehmeyer S, et al. Performance of five D-dimer assays for the exclusion of symptomatic distal leg vein thrombosis. Thromb Haemost. 2012; 107: 369-378. PMid: 22234425. http://dx.doi.org/10.1160/TH11-07-0511

[9] Bauersachs RM, Riess H, Hach-Wunderle V, Gerlach H, Carnarius H, Eberle S, et al. Impact of gender on the clinical presentation and diagnosis of deep-vein thrombosis. Thromb Haemost. 2010; 103: 710-717. PMid: 20174769. http://dx.doi.org/10.1160/TH09-10-0705

[10] Schellong SM, Gerlach H, Hach-Wunderle V, Rabe E, Riess H, Carnarius H, et al. Diagnosis of deep-vein thrombosis: adherence to guidelines and outcomes in real-world health care. Thromb Haemost. 2009; 102: 1234-1240. PMid: 19967156.

[11] Bauersachs R. TULIPA-Register - Erste Daten zur Versorgungssituation bei Thrombosen. Notfall \& Hausarztmedizin. 2006; 32: 531. http://dx.doi.org/10.1055/s-2006-958486

[12] The EINSTEIN. Investigators N Engl J Med. 2010; 363: 2499-2510 (Supplementary Appendix).

[13] Bruscas MJ, Nieto JA, Perez-Pinar M, López-Jiménez L, Fernández-Capitán C, López-Chuliá F, et al. RIETE Investigators. Suboptimal doses of low molecular weight heparin and acute venous thromboembolism. Data from the RIETE registry. Ann Hematol. 2007; 86: 519-26. PMid: 17437112. http://dx.doi.org/10.1007/s00277-007-0282-x

[14] Wells PS, Anderson D. The diagnosis and treatment of venous thromboembolism. Hematology Am Soc Hematol Educ Program. 2013; 2013: 457-63. PMid: 24319219. http://dx.doi.org/10.1182/asheducation-2013.1.457 